\title{
Recent decline in life expectancy at birth in Slovenia
}

\author{
Aleša Lotrič Dolinar ${ }^{1} \quad$ Jože Sambt $^{2}$
}

\begin{abstract}
For many decades, life expectancy at birth $\left(e_{0}\right)$ in Slovenia has been increasing at a very rapid pace. However, in 2015, $e_{0}$ declined slightly; it recovered in 2016, but fell again in 2017 for women. In the same period, a pause in declining mortality was observed in numerous developed countries worldwide. It is too early to provide a thorough analysis and firm conclusions, but we shed some light on the topic by decomposing the observed decline in Slovenia by age and cause of death. In particular, using a life table model and life expectancy decomposition technique, we analyse what cause of death for what age group contributed the most to this decline in life expectancy at birth. We show that the main reason for the recent drop in life expectancy at birth in Slovenia was higher mortality due to external causes for men of all ages and due to neoplasms for women above 60 years and men above 50 years.
\end{abstract}

\section{Introduction}

We have been living in times of remarkably increasing human longevity. In developed countries, the best-performance life expectancy at birth has been increasing by about 2.5 years per decade for around 180 years. During this period, the highest life expectancy at birth has almost doubled - from about 45 years in 1840 for Swedish women (Oeppen and Vaupel, 2002) to more than 87 years in 2018 for Japanese women (OECD Data). For the whole world and both sexes, life expectancy more than doubled from around 30 years in 1900 to 65 years by 2000 (Lee, 2003).

The increase in longevity is related to the demographic transition which is one of the central concepts in demography. The demographic transition starts with a mortality decline and is later followed by a decline in fertility. This delay in fertility decline

\footnotetext{
${ }^{1}$ School of Economics and Business, University of Ljubljana, Ljubljana, Slovenia; alesa.lotric.dolinar@ef.uni-lj.si

${ }^{2}$ School of Economics and Business, University of Ljubljana, Ljubljana, Slovenia; joze.sambt@ef.uni-lj.si
} 
compared with the mortality decline leads to a fast population growth. When mortality and fertility stabilize at low levels, the population growth decreases (or even becomes negative) and we witness population ageing. This is the current situation in developed countries, whereas developing countries are still at different stages of the demographic transition.

Until 1950, the gain in life expectancy came mostly from the mortality decline at younger ages (Oeppen and Vaupel, 2002) due to the lower impact of contagious and infectious diseases as a consequence of improved personal hygiene, the widely known germ theory of disease, and preventive medicine including vaccines (Lee, 2003). Later, the increase in longevity was due to the reduction of chronic and degenerative diseases, especially heart diseases and cancer (Riley, 2001) and, in the later part of the $20^{\text {th }}$ century, due to biomedical research (Lee, 2003) for ages 65 and above (Oeppen and Vaupel, 2002). Life expectancy also depends on epidemics, wars and economic recessions, but since 1950 the impact of these events in the most developed countries has been negligible (Mayhew and Smith, 2015). Some scholars argue that in the future life expectancy at birth may even rise to close to 100 years (Ediev, 2011; Mayhew and Smith, 2015).

In Slovenia, the increase in life expectancy was substantial during the second half of the $20^{\text {th }}$ century, but was interrupted twice. In the 1960 s the prolongation of life expectancy slowed down for women and even regressed for men, because in medicine the progress in decreasing mortality from the use of antibiotics was brought to an end and degenerative and social diseases needed to be dealt with. Male mortality began to decrease again only in 1980s. Slovenia experienced another stage of stagnation in life expectancy in the first half of 1990s when mortality rates increased for the middle-aged population of both sexes, what was attributed mainly to a significant increase in unemployment in that time (Hlebec and Šrcelj, 2011). In the second half of the 1990s, mortality began to decrease again in all age groups. Consequently, in the period 1993/942003/2004 life expectancy at birth increased by 3.9 and 3.7 years for men and women, respectively, and in the following ten years again by 4.5 years for men and by 2.6 years for women (SURS SiStat Database).

However, in 2015, Slovenia and many developed countries worldwide experienced a substantial drop in life expectancy at birth, as presented in Figure 1 for Slovenia and the European Union.

From the Eurostat database (Eurostat Data 1) it is clear that in 2015 almost all EU countries experienced a drop in life expectancy at birth (except Finland, Latvia, Luxembourg, and Portugal, where there was no change).

So far, not much research has been published on this phenomenon in Europe. However, a paper about the drop in life expectancy at birth in France (Mazuy et al., 2016) reveals that the most probable reason was the influenza epidemic in that particular year. Apart from a relatively ineffective vaccine for the influenza season that year, the epidemic was long and concentrated in the first months of 2015 rather than being spread 


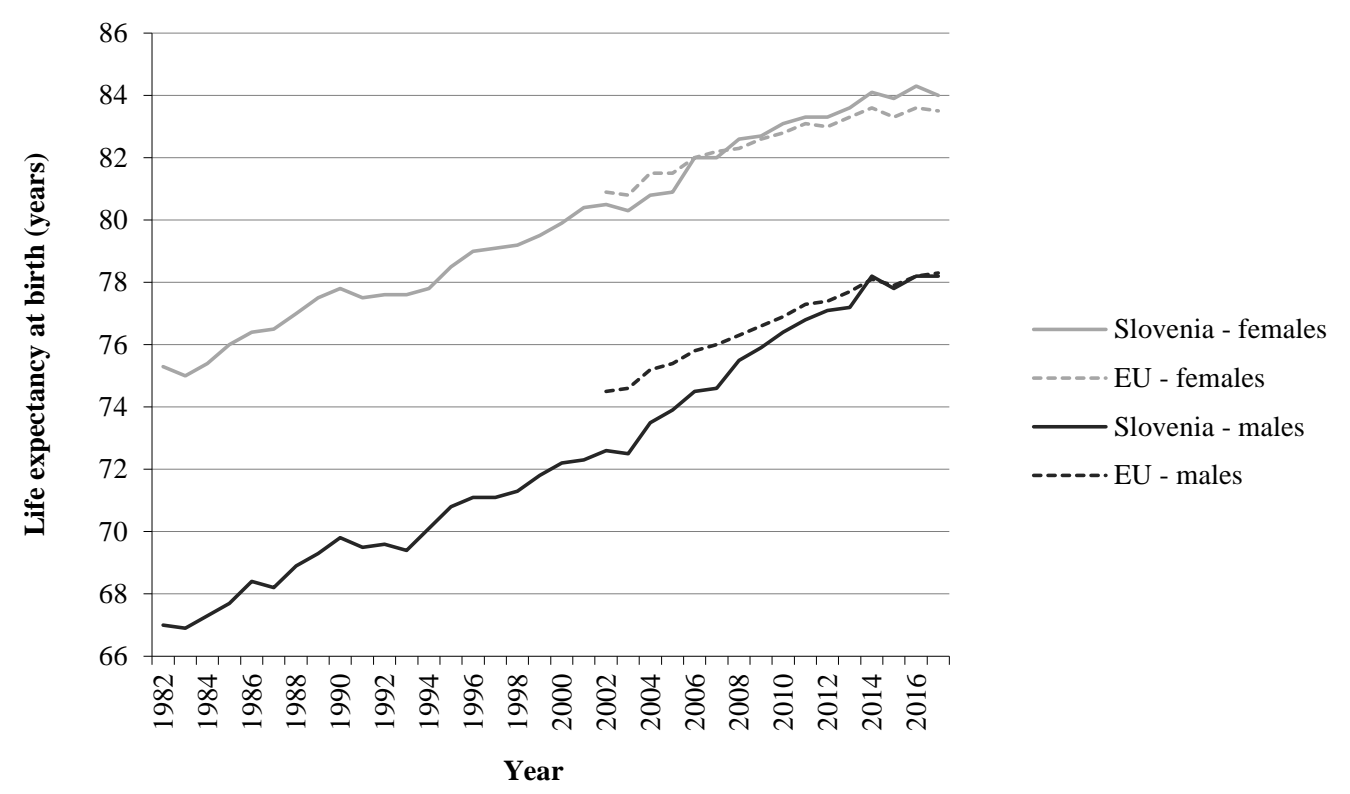

Figure 1: Life expectancy at birth for Slovenia from 1982 and for EU from 2002 onward, by sex. Source: Eurostat (Eurostat Data 1)

throughout the winter months of 2014-2015. A more comprehensive research study carried out by Ho and Hendi (2018), which covered 18 developed countries (12 EU countries, Norway, Switzerland, Japan, Australia, Canada, and the USA), reports that the average decline in life expectancy at birth for these countries in 2015 was 0.21 years for women and 0.18 years for men. Such simultaneous large declines for so many countries are rather unusual in demographic history. Ho and Hendi also found that in the majority of countries these declines in life expectancy were mostly a result of increased mortality at older ages ( $\geq 65$ years) related to respiratory disease, cardiovascular disease, nervous system disease, and mental disorders. Most of the analysed countries experienced robust gains in life expectancy in the year 2016 which more than compensated for the 2015 decline. However, the United Kingdom and the United States appear to be experiencing stagnating or continued declines in life expectancy, which raises questions about trends from socioeconomic, healthcare service, and behavioural point of view in these countries. In the study by Ho and Hendi (2018), an important limitation is mentioned which also applies to all other similar studies. Specifically, influenza may be underreported on death certificates and this is more prevalent at older ages where it is more difficult to exactly define the cause of death (Reed et al., 2015). Therefore, at higher ages, the causes of death become more correlated, which is also known as the competing risks problem (Tsiatis, 1975). This problem is generally taken care of by using broader groups of causes of death. Another potential problem when comparing mortalities by different causes of death across countries is the comparability of cause of 
death coding; this also needs to be kept in mind when interpreting the results.

In our paper, we show that Slovenia, too, experienced a substantial drop in life expectancy at birth in 2015 as well as another one in 2017 (for women only). In addition, we decompose this drop by age group and cause of death simultaneously in order to determine the age groups and causes of death which were the main reasons for higher mortality in the two mentioned years. It turns out that our results for Slovenia differ from findings for other countries.

\section{Data and methods}

Mortality analysis builds upon the number of recorded deaths in the population. By dividing the number of deaths by the total midyear population (and multiplying by one thousand) we derive the basic indicator of mortality - the crude death rate. Observing the crude death rate over time is an inappropriate measure because it depends on the age structure of a given population. A population with the same mortality by age but with a higher share of elderly people faces a larger crude death rate. Life expectancy at birth is independent of population age structure and it is very informative per se. Therefore, life expectancy at birth is the most frequently used measure of longevity and shows how many years a newborn is expected to live, assuming unchanged mortality at different ages in a given year.

To analyse the decline in life expectancy at birth we use sex-, age-, and causespecific number of deaths provided by NIJZ (2019) and the number of people by age and sex from SURS (2019) for each year from 2014 to 2017; 2017 is the latest available year to date.

We use 5-year-age-group data, whereby the first age group is divided into two: up to 1 year and 1-4 years, because the mortality of newborns is much higher compared with young children from 1 year on. The last age group includes people aged 85 years or more, resulting in 19 age groups altogether.

We base our analysis on five main groups of causes of death, according to ICD-10 (2016), which cover almost $90 \%$ of all deaths in Slovenia in the analysed period: neoplasms, diseases of the circulatory system, diseases of the respiratory system, diseases of the digestive system, and external causes. All other causes of death are included in the sixth group called 'Other'. Figure 2 presents age-standardized cause-specific mortality rates for Slovenia and EU-28 for 2015; this is the latest available data for age-standardized cause-specific mortality rates (Eurostat Data 2).

Life expectancy at birth is derived from the life table, which is a demographic model that builds upon the age-specific mortality rates of an actual population in a given year (Poston and Bouvier, 2017; Siegel, Swanson and Shryock, 2004). Mortality rates of an actual population in an analysed year are transformed into different life-table functions that change with age (Malačič, 2006; Kintner, 2003). The base is age-, sex-, and cause- 


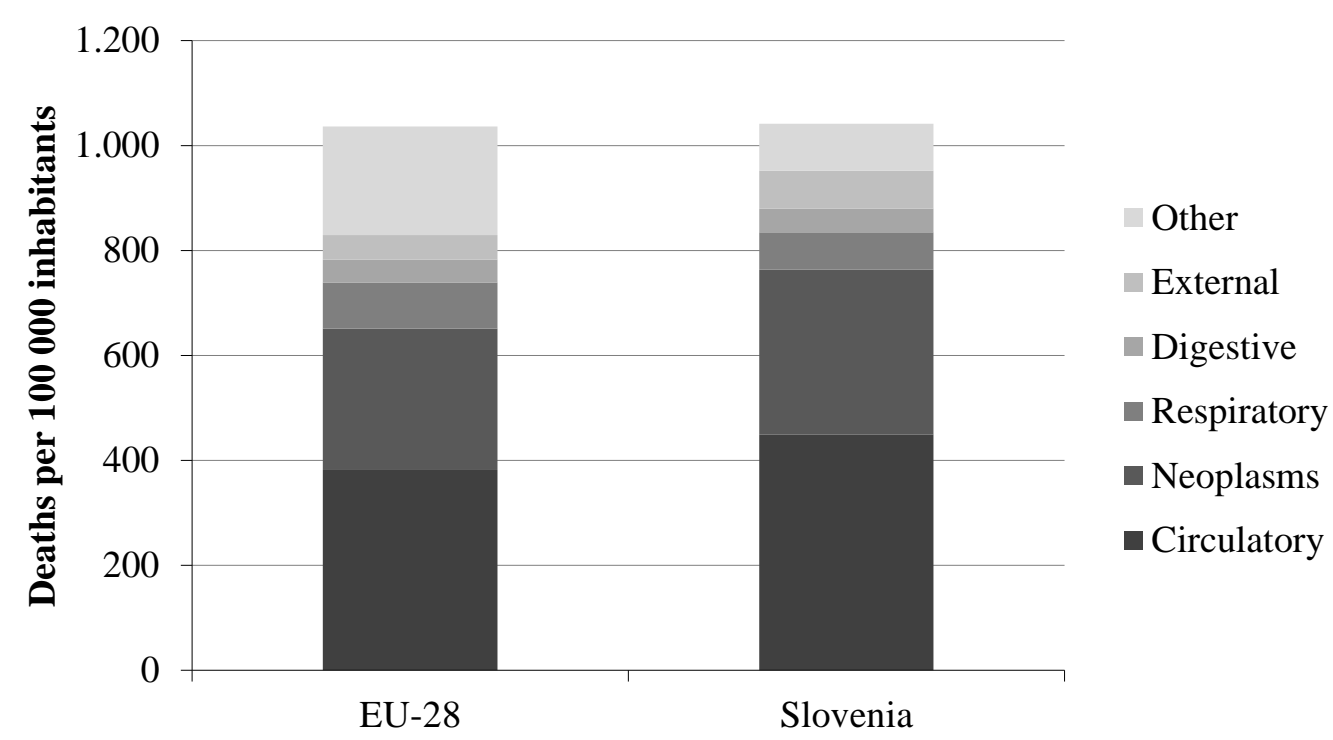

Figure 2: Age-standardized cause-specific mortality rates (deaths per 100000$)$ for five main groups of causes of death for Slovenia and EU in 2015. Source: Eurostat (Eurostat Data 2)

specific mortality rate ${ }_{n} m_{x}$ :

$$
{ }_{n} m_{x}=\frac{{ }_{n} M_{x}^{t}}{\frac{{ }_{n} P_{x}^{t}+{ }_{n} P_{x}^{t+1}}{2}},
$$

where ${ }_{n} M_{x}$ is the number of deaths and ${ }_{n} P_{x}$ the number of persons alive on the $1^{\text {st }}$ of January. From here, we calculate the probability of dying

$$
{ }_{n} q_{x}=\frac{2 n_{n} m_{x}}{2+n_{n} m_{x}}
$$

within the specified age interval $(x, x+n)$, the number of survivors at the beginning of this age interval

$$
l_{x}=\left(1-{ }_{n} q_{x-n}\right) l_{x-n}
$$

and the number of person-years lived ${ }^{3}$ within this age interval

$$
{ }_{n} L_{x}=\frac{n\left(l_{x}+l_{x+n}\right)}{2},
$$

which is summed up into the total number of person-years lived after age $x$

$$
T_{x}=\sum_{i=x}^{\omega}{ }_{n} L_{i},
$$

\footnotetext{
${ }^{3}$ Because the assumption of linear dying-off for the first age group (infants under the age of 1 year) is unrealistic because the probability of death is much higher immediately after birth, the number of personyears for the first age interval is calculated as $L_{0}=0.1 \times l_{o}+0.9 \times l_{1}$, based on the experience and observation of developed countries with low infant mortality.
} 
which finally results in the life expectancy function

$$
e_{x}=\frac{T_{x}}{l_{x}}
$$

Life expectancy shows the number of years persons who lived up to age $\mathrm{x}$ can expect to live if the mortality rates at each age from a given year onward remain unchanged in the future. Thus, $e_{x}$ hypothetically extrapolates the mortality pattern from the given year to the whole remaining lifetime of an individual.

Because life tables do not assume a specific age distribution but develop from an arbitrarily set initial population size (usually 100000), they are comparable between countries and between different points in time. Most often, we are interested in life expectancy at birth $\left(e_{0}\right)$ which is one of the most common indicators of mortality and also a country's health and demographic situation.

Our main goal in the present paper is to analyse the decline in $e_{0}$ which was observed between the years 2014 and 2015 for both sexes and also between 2016 and 2017 for women. The change in $e_{0}$ from an age perspective can be analysed using two common decomposition methods by Arriaga (1984) and Pollard (1988). The two approaches are mathematically equivalent; however, various discrete approximations give slightly different results. The contribution of older age groups is underestimated in Arriaga's method (Beltrán-Sánches, Preston and Canudas-Romo, 2008), but the total of partial contributions does not precisely add up in Pollard's method (Ponnapalli, 2005), because it uses approximate formulae derived from the continuous approach. Pressat (1985), however, suggested a different weighting formula that ensures the correct summation of $e_{0}$ difference across age groups:

$$
e_{0}^{A}-e_{0}^{B} \cong \frac{\sum_{x=0}^{\omega}\left(\frac{l_{x}^{B}+l_{x}^{A}}{2}\left(e_{x}^{A}-e_{x}^{B}\right)-\frac{l_{x+n}^{B}+l_{x+n}^{A}}{2}\left(e_{x+n}^{A}-e_{x+n}^{B}\right)\right)}{100000}
$$

with the usual life-table notations and $A$ and $B$ representing compared entities. Simultaneous decomposition by cause of death is then calculated according to the Arriaga (1995) approach, where causes of death need to be separated into exhaustive and mutually exclusive groups (hence the need for the additional group of all other causes). With this approach it is assumed that the individual cause's relative contribution to life expectancy change in a certain age group is equal to the proportion of mortality change due to this cause in total mortality change for the same age group:

$$
{ }_{c} S A C_{j}\left({ }_{n} e_{x}\right)=S A C_{j}\left({ }_{n} e_{x}\right) \frac{{ }_{c} C_{j}}{C_{j}}
$$

where $c$ is the specific cause of death, $j$ is the specific age group, ${ }_{c} C_{j}={ }_{c} m_{j}^{t+i}-{ }_{c} m_{j}^{t}$ and $C_{j}=\sum_{c}{ }_{c} C_{j}$. 
Decomposition of $e_{0}$ changes for Slovenia has been carried out before (Lotrič Dolinar, Došenović Bonča, and Sambt, 2017) but the time series in that analysis ended with the year 2014. For the time span up to 2014, the main source of $e_{0}$ increase was primarily lower mortality from diseases of the circulatory system in older age groups, which is in line with cardiovascular revolution theory (Eggleston and Fuchs, 2012). However, after 2014 , the situation changed and this study reveals the reasons for this change.

\section{Results}

Table 1 shows the changes in life expectancy at birth in Slovenia for the period 2014-2017.

Table 1: Life expectancy at birth ( $e_{0}$, in years), 2014-2017, Slovenia, by sex

\begin{tabular}{lcccc}
\hline Year & 2014 & 2015 & 2016 & 2017 \\
\hline Females & 84.06 & 83.84 & 84.17 & 83.99 \\
Males & 78.16 & 77.75 & 78.13 & 78.22 \\
\hline
\end{tabular}

In 2015, life expectancy at birth fell by 0.22 and 0.40 years for women and men, respectively. The $e_{0}$ recovered in 2016, but fell again in 2017 by 0.18 years for women and, therefore, the $e_{0}$ in 2017 for women was still below the $e_{0}$ in 2014.

The decomposition of these changes in $e_{0}$ by contributions of individual age groups and individual causes of death is presented in Tables 2, 3 and 4.

In 2015, compared with 2014, the mortality situation mostly deteriorated due to increased mortality from external causes for men in general, as well as due to neoplasms for women above 30 years of age, especially in the age group 65-74, and due to neoplasms for men above 50 years of age. The situation was also worse because of other causes of death for men in general and for women above 50 years, and because of circulatory diseases-related mortality for men between 70 and 84 years. Mortality from respiratory diseases also increased for women (especially older women) but much less than from the aforementioned causes. However, this decline in life expectancy was somewhat compensated by lower mortality from circulatory diseases for women aged 70-84 and for the oldest old men, as well as by other causes for newborn girls. However, the latter number is quite prone to randomness because the total number of infant deaths itself is already very low.

As shown in Table 3, mortality generally decreased in 2016, mostly because of lower mortality from circulatory diseases for women above 65 years of age and for men above 60 years of age, but also because of lower mortality from neoplasms for men.

However, as presented in Table 4, in 2017 the long-run increase of the $e_{0}$ trend for women reversed again — substantially so-whereas it stayed approximately at the same level for men. 
Table 2: Contribution of each age group and each cause of death to $e_{0}$ change between 2014 and 2015 (in years), Slovenia, by sex; darker colour denotes more than 0.03 years of decline, whereas a lighter shade denotes more than 0.03 years of increase

\begin{tabular}{|c|c|c|c|c|c|c|c|c|c|c|c|c|c|c|}
\hline \multirow[b]{2}{*}{$\begin{array}{c}\text { Age } \\
\text { group }\end{array}$} & \multicolumn{7}{|c|}{ Females (total change $=-0.22$ years) } & \multicolumn{7}{|c|}{ Males (total change $=-0.40$ years) } \\
\hline & $\begin{array}{c}\text { All } \\
\text { causes }\end{array}$ & Circ. & Neo. & Ext. & Resp. & Dig. & Other & $\begin{array}{c}\text { All } \\
\text { causes }\end{array}$ & Circ. & Neo. & Ext. & Resp. & Dig. & Other \\
\hline 0 & & -0.01 & & & & & & & & -0.01 & & 0.00 & 0.00 & 0.01 \\
\hline $1-4$ & 0.01 & 0.00 & 0.00 & 0.00 & 0.00 & 0.00 & -0.01 & -0.03 & 0.00 & -0.01 & & 0.00 & 0.00 & -0.01 \\
\hline $5-9$ & .01 & 0.00 & 0.02 & 0.00 & 0.00 & 0.00 & -0.02 & & 0.00 & 0.00 & 0.01 & -0.01 & 0.00 & 0.01 \\
\hline $10-14$ & 01 & 0.00 & -0.01 & & 0.00 & & 0.01 & & & 0.01 & & 0.00 & 0.00 & -0.02 \\
\hline $15-19$ & -0.01 & 0.00 & 0.01 & 0.00 & 0.00 & 0.00 & -0.02 & & 0.01 & -0.02 & & 0.00 & 0.00 & 0.01 \\
\hline $20-24$ & 0.01 & -0.01 & 0.02 & 0.0 & 0.00 & 0.00 & 0.01 & -0.05 & -0.01 & 0.00 & -0. & 0.00 & 0.00 & -0.01 \\
\hline $25-29$ & & 0.00 & & & & & & & & -0. & & & 0.00 & -0.02 \\
\hline $30-34$ & -0.01 & 0.00 & -0.03 & 0. & 0.00 & 0 . & & & 0.00 & -0.01 & -0 & 0 . & 01 & 0.01 \\
\hline $35-39$ & 0 & 0.00 & -0.02 & 0.02 & 0.00 & 0.0 & 0.00 & & 0.02 & 0.00 & -0 & 0. & 0.00 & 0.01 \\
\hline $40-44$ & -0.01 & -0.01 & & -0.01 & 0.00 & 0.00 & -0.01 & -0.05 & -0.02 & 0.00 & -0. & 0.00 & 0.01 & -0.02 \\
\hline $45-49$ & -0.01 & 0.02 & -0.02 & -0.0 & 0.00 & 0. & 0.00 & -0.03 & -0.01 & -0.01 & 0.00 & -0.01 & 0.00 & -0.01 \\
\hline $50-54$ & -0.03 & 0.01 & 0.00 & 0.00 & 0.00 & 0.00 & -0.03 & -0.07 & -0.02 & -0.04 & -0.01 & 0.00 & 0.02 & -0.02 \\
\hline $55-59$ & & -0.01 & -0.01 & 0.00 & -0.01 & 0.01 & 0.01 & -0.02 & 0.00 & -0.02 & 0.00 & -0.01 & 0.03 & -0.02 \\
\hline $60-64$ & -0.01 & 0.00 & -0.02 & -0.01 & & & & & & 0.00 & -0.03 & 0.00 & 0.00 & 0.00 \\
\hline $65-69$ & -0.12 & -0.01 & -0.07 & -0.02 & 0.01 & -0.01 & -0.03 & -0.01 & 0.03 & -0.03 & 0.00 & -0.01 & 0.01 & -0.02 \\
\hline $70-74$ & -0.01 & 0.02 & -0.03 & -0.03 & 0.00 & 0.01 & 0.02 & -0.05 & -0.03 & 0.00 & 0.01 & 0.00 & 0.00 & -0.03 \\
\hline $75-79$ & -0.01 & -0.01 & 0.00 & 0.00 & -0.02 & 0.02 & 0.00 & -0.03 & 0.00 & -0.04 & -0.01 & 0.01 & 0.01 & -0.01 \\
\hline $80-84$ & & 0.04 & 0.02 & -0.02 & -0.02 & 0.01 & -0.03 & -0.04 & -0.04 & 0.03 & 0.00 & -0.02 & 0.01 & -0.03 \\
\hline $85+$ & -0.05 & -0.02 & -0.02 & 0.03 & -0.03 & 0.00 & -0.01 & 0.01 & 0.06 & -0.02 & -0.04 & 0.00 & 0.00 & 0.02 \\
\hline All ages & -0.22 & 0.01 & -0.13 & -0.03 & -0.08 & 0.05 & -0.04 & -0.40 & 0.03 & -0.16 & -0.19 & -0.04 & 0.11 & -0.15 \\
\hline
\end{tabular}

Note: Explanation of abbreviations for causes of death: Circ. = diseases of the circulatory system, Neo. = neoplasms, Ext. = external causes of morbidity and mortality, Resp. = diseases of the respiratory system, Dig. = diseases of the digestive system, Other $=$ all other causes 
Table 3: Contribution of each age group and each cause of death to $e_{0}$ change between 2015 and 2016 (in years), Slovenia, by sex; darker colour denotes more than 0.03 years of decline, whereas a lighter shade denotes more than 0.03 years of increase

\begin{tabular}{|c|c|c|c|c|c|c|c|c|c|c|c|c|c|c|}
\hline \multirow[b]{2}{*}{$\begin{array}{l}\text { Age } \\
\text { group }\end{array}$} & \multicolumn{7}{|c|}{ Females $($ Total change $=0.33$ years $)$} & \multicolumn{7}{|c|}{ Males $($ Total change $=0.38$ years $)$} \\
\hline & $\begin{array}{c}\text { All } \\
\text { causes }\end{array}$ & Circ. & Neo. & Ext. & Resp. & Dig. & Other & $\begin{array}{c}\text { All } \\
\text { causes }\end{array}$ & Circ. & Neo. & Ext. & Resp. & Dig. & Other \\
\hline 0 & -0.05 & & & -0.01 & 001 & & & -0.02 & & 0.01 & 0.00 & -0.02 & 0.00 & 0.00 \\
\hline $1-4$ & .03 & 0.00 & -0.01 & -0.01 & 0.00 & 0.00 & -0.02 & & -0.01 & -0.01 & 0.01 & 0.00 & 0.00 & 0.02 \\
\hline $5-9$ & 0.02 & 0.00 & 0.00 & 0.01 & 0.00 & 0.00 & 0.01 & 0.01 & 0.00 & 0.01 & 0.00 & 0.01 & 0.00 & 0.00 \\
\hline $10-14$ & & 0.00 & & & & & & & 00 & -0.01 & -0.01 & 0.00 & 0.00 & 0.02 \\
\hline $15-19$ & -0.06 & 0.01 & -0.03 & -0.04 & 0.00 & & & -0 & 0.00 & 0.02 & -0.04 & 0.00 & 0.00 & 0.00 \\
\hline $20-24$ & 0.03 & 0.01 & 0.00 & 0.02 & 0.00 & 0.00 & 0.00 & -0.06 & 0.00 & -0.01 & -0.04 & -0.01 & 0.00 & 0.00 \\
\hline $25-29$ & -0.02 & 0.00 & -0.02 & -0.0 & 0.00 & 0.0 & & 0.00 & -0.01 & 0.01 & -0.01 & 0.00 & 0.00 & 0.00 \\
\hline $30-34$ & 0.0 & 0.00 & 0.02 & -0.02 & 0.00 & 0.01 & 0.00 & -0.01 & -0. & 0.01 & 0.01 & 0.00 & -0.01 & -0.01 \\
\hline $35-39$ & 0.02 & -0.01 & 0.04 & 0.00 & 0.00 & -0.01 & -0.0 & 0.00 & -0.02 & 0.01 & -0.01 & $0 .($ & 0.01 & 0.00 \\
\hline $40-44$ & 0.02 & 0.01 & -0.02 & 0.00 & 0.00 & 0.01 & 0.0 & 0.09 & 0.01 & 0.02 & 0.02 & 0.00 & 0.00 & 0.02 \\
\hline $45-49$ & 0.05 & 0.00 & 0.03 & 0.03 & 0.00 & 0.00 & -0.0 & 0.02 & -0.02 & 0.0 & 0.01 & 0.01 & 0.01 & 0.00 \\
\hline $50-54$ & 0.02 & -0.01 & -0.01 & -0.01 & 0.01 & 0.01 & 0.03 & 0.04 & 0.00 & 0.03 & 0.02 & 0.01 & -0.01 & -0.01 \\
\hline $55-59$ & 0.00 & 0.01 & 0.03 & -0.02 & 0.00 & -0.01 & -0.01 & 0.02 & 0.01 & 0.01 & -0.01 & 0.00 & 0.00 & 0.01 \\
\hline $60-64$ & 0.03 & -0.01 & & & & 0.02 & -0.01 & & 0.03 & 0.02 & 0.01 & -0.01 & 0.01 & -0.02 \\
\hline $65-69$ & 0.11 & 0.07 & 0.0 & 0.0 & 0.00 & 0.00 & 0.01 & -0.03 & 0.01 & -0.04 & 0.00 & 0.01 & -0.01 & 0.00 \\
\hline $70-74$ & 0.01 & 0.01 & 0.00 & 0.01 & 0.01 & 0.01 & -0.02 & 0.12 & 0.07 & -0.01 & 0.00 & 0.02 & 0.01 & 0.02 \\
\hline $75-79$ & 0.10 & 0.06 & 0.01 & 0.00 & 0.02 & -0.01 & 0.01 & 0.06 & 0.03 & 0.04 & 0.00 & -0.02 & 0.01 & 0.00 \\
\hline $80-84$ & 0.06 & 0.02 & 0.03 & 0.01 & 0.00 & -0.01 & 0.01 & 0.08 & 0.07 & -0.02 & 0.00 & 0.01 & -0.01 & 0.02 \\
\hline $85+$ & 0.00 & 0.10 & -0.04 & -0.01 & -0.01 & -0.01 & -0.02 & 0.02 & -0.04 & 0.02 & 0.00 & 0.04 & 0.00 & 0.00 \\
\hline All ages & 0.33 & 0.28 & 0.08 & 0.00 & 0.04 & 0.01 & -0.07 & 0.38 & 0.13 & 0.13 & -0.02 & 0.05 & 0.02 & 0.07 \\
\hline
\end{tabular}

Note: Explanation of abbreviations for causes of death: Circ. $=$ diseases of the circulatory system, Neo. $=$ neoplasms, Ext. $=$ external causes of morbidity and mortality, Resp. = diseases of the respiratory system, Dig. = diseases of the digestive system, Other $=$ all other causes 
Table 4: Contribution of each age group and each cause of death to $e_{0}$ change between 2016 and 2017 (in years), Slovenia, by sex; darker colour denotes more than 0.03 years of decline, whereas a lighter shade denotes more than 0.03 years of increase

\begin{tabular}{|c|c|c|c|c|c|c|c|c|c|c|c|c|c|c|}
\hline \multirow[b]{2}{*}{$\begin{array}{l}\text { Age } \\
\text { group }\end{array}$} & \multicolumn{7}{|c|}{ Females $($ Total change $=-0.18$ years $)$} & \multicolumn{7}{|c|}{ Males $($ Total change $=0.08$ years $)$} \\
\hline & $\begin{array}{c}\text { All } \\
\text { causes }\end{array}$ & Circ. & Neo. & Ext. & Resp. & Dig. & Other & $\begin{array}{c}\text { All } \\
\text { causes }\end{array}$ & Circ. & Neo. & Ext. & Resp. & Dig. & Other \\
\hline 0 & & & & & & & & -001 & & 0.00 & -0.01 & 0.02 & 0.00 & -0.02 \\
\hline $1-4$ & 0.03 & 0.00 & 0.00 & 0.0 & 0.00 & 0.0 & & 0.03 & 0.01 & 0.01 & -0.01 & 0.00 & 0.00 & 0.01 \\
\hline $5-9$ & -0.01 & 0.00 & -0.01 & 0.00 & 0.00 & 0.00 & 0 & -0.01 & 0.00 & -0.01 & 0.00 & 0.00 & 0.00 & 0.00 \\
\hline $10-14$ & .02 & 0.00 & -0.01 & -0.01 & & & & & & & 0.01 & & 0.00 & 0.02 \\
\hline $15-19$ & & 0.00 & 0.01 & 0.02 & -0.01 & & & 0.0 & 0.00 & -0.01 & 0.07 & & 0.00 & 0.01 \\
\hline $20-24$ & -0.05 & 0.00 & -0.01 & -0.04 & 0.00 & 0.00 & -0.01 & 0.08 & 0.01 & -0.01 & 0.10 & 0.01 & 0.00 & -0.02 \\
\hline $25-29$ & 0 & 0.00 & 0.01 & -0.01 & 00 & 0. & & -0.0 & 0.00 & -0.01 & -0 & & 0.00 & 0.02 \\
\hline $30-34$ & 0.03 & 0.00 & 0.01 & 0. & 0.00 & 0.00 & & 0. & 0.01 & -0 & 0. & 0. & 0.00 & 0.01 \\
\hline $35-39$ & 0.00 & 0.00 & -0.03 & 0.02 & 0.00 & 0. & & & 0. & 0. & 0.04 & 0. & 0.00 & 0.00 \\
\hline $40-44$ & -0.01 & 0.00 & 0.02 & -0.01 & 0.00 & 0.00 & -0.03 & -0.01 & 0.01 & -0.01 & $0 .($ & 0.00 & -0.02 & -0.01 \\
\hline $45-49$ & -0.02 & 0.01 & -0.02 & -0.0 & 0.00 & 0.00 & 0.0 & 0.0 & 0. & 0.01 & 0.00 & 0.00 & 0.00 & -0.01 \\
\hline $50-54$ & -0.01 & -0.01 & 0.02 & -0.01 & -0.01 & 0.00 & -0.01 & 0.03 & 0.00 & 0.04 & -0.02 & 0.00 & 0.02 & -0.01 \\
\hline $55-59$ & -0.04 & 0.00 & -0.09 & 0.01 & 0.00 & 0.02 & & 0.03 & 0.01 & 0.01 & -0.01 & 0.01 & 0.01 & 0.00 \\
\hline & -0.04 & 0.02 & -0.02 & -0.01 & -0.01 & -0.01 & -0.02 & -0.03 & -0.03 & -0.01 & 0.01 & 0.00 & 0.00 & -0.01 \\
\hline $65-69$ & -0.06 & -0.04 & -0.01 & 0.01 & 0.00 & 0.00 & -0.02 & 0.04 & 0.02 & 0.04 & 0.01 & -0.01 & 0.01 & -0.02 \\
\hline $70-74$ & 0.04 & 0.05 & 0.03 & -0.01 & -0.02 & -0.01 & -0.01 & -0.04 & 0.00 & 0.03 & -0.01 & 0.01 & -0.02 & -0.05 \\
\hline $75-79$ & -0.08 & 0.01 & -0.02 & -0.01 & 0.00 & -0.01 & -0.05 & -0.05 & -0.03 & -0.01 & 0.00 & 0.03 & 0.01 & -0.05 \\
\hline $80-84$ & -0.02 & 0.01 & -0.02 & -0.01 & 0.01 & & -0.01 & -0.04 & -0.01 & 0.01 & -0.02 & 0.00 & 0.00 & -0.01 \\
\hline $85+$ & 0.04 & 0.05 & 0.03 & -0.06 & 0.03 & 0.02 & -0.02 & -0.15 & -0.03 & -0.01 & -0.03 & -0.03 & -0.02 & -0.01 \\
\hline All ages & -0.18 & 0.09 & -0.09 & -0.10 & 0.00 & 0.02 & -0.11 & 0.08 & 0.02 & 0.05 & 0.14 & 0.03 & -0.02 & -0.14 \\
\hline
\end{tabular}

Note: Explanation of abbreviations for causes of death: Circ. = diseases of the circulatory system, Neo. = neoplasms, Ext. = external causes of morbidity and mortality, Resp. = diseases of the respiratory system, Dig. = diseases of the digestive system, Other $=$ all other causes 
For women, the additional drop in $e_{0}$ was again caused mainly by higher mortality from neoplasms for ages above 35, especially in the age group 55-59, but also due to external causes in the age groups 20-24 and 85+, along with other causes for women above 60 years of age. Again, the improved situation of circulatory diseases for women above 70 years of age considerably compensated for this drop.

The most severe drop in $e_{0}$ for men was induced by other causes for men above 60 years, but was more than compensated for by improved situations elsewhere, especially in relation to external causes for young men aged 15-24.

\section{Summary and conclusion}

The length of human life has been increasing very quickly for the last 180 years. Until 1950, this was mostly due to lower mortality from contagious diseases. Later, the increase in longevity was mainly the consequence of better treatment of chronic and degenerative diseases, like diseases of the circulatory system and cancer, but also due to biomedical research (Riley, 2001; Lee, 2003).

Although some researchers (Ediev, 2011; Mayhew and Smith, 2015) argue that life expectancy at birth $\left(e_{0}\right)$ will rise further, the pace has been slowing down in recent years and, in developed countries, it even shows stagnation. A few studies have found that the main reason for the substantial drop in life expectancy at birth in Europe in 2015 was a severe influenza in the winter of 2014-2015, which was concentrated mostly in the first months of 2015.

Life expectancy at birth also decreased considerably in 2015 (and again in 2017 for women) in Slovenia. Using the $e_{0}$ decomposition method, we show that the main reason for this was increased mortality from external causes of death for men at all ages and neoplasms for older people of both sexes. A drop in $e_{0}$ due to respiratory diseases is also noticeable for older women, but not to such an extent as that due to neoplasms. The $e_{0}$ recovered in 2016, mainly due to lower mortality from circulatory diseases for older people of both sexes, as well as due to neoplasms for men. However, $e_{0}$ fell again in 2017 for women, especially because of neoplasms, external causes, and other causes of death. Increased mortality from other causes of death in 2017 was mainly concentrated in older age groups; that holds for men, too.

It turns out that, in Slovenia, the bad influenza season and related respiratory complications of 2015 did not have such a strong effect as in other countries analysed to date. Of course, we need to keep in mind that recording causes of death is not completely comparable across countries because the coding of causes of death may not be perfectly harmonized. Also, it is often difficult to state one main cause of death, especially in older ages when people tend to have more than one disease.

We show that in Slovenia the weakness that has been slowing down the increase in longevity in the past several years are neoplasms for both sexes and external causes 
of death for men, along with other causes of death for both sexes in older age groups, when other causes of death are mainly various dementias and other diseases of the nervous system (Eurostat Data 2). However, as Scherbov and Ediev (2011) point out, it is important to take the size of the population into account before making any final conclusions, because standard errors of estimates of life expectancy decrease as an inverse square root of population size as population increases (Scherbov and Ediev, 2011). Because the Slovenian population is fairly small, the observed increase in mortality might also be strongly affected simply by random factors and, thus, needs to be further monitored over the coming years.

Nevertheless, the data show that the main source of potential life expectancy prolongation nowadays lies within the older age groups. At the same time, in ageing societies an increasingly high proportion of the elderly compared to the young represents not only an important demographic change but needs to be addressed also from social, economic and health-care perspective. Decreasing ratio between active and dependent population challenges the sustainability of the public system. A higher proportion of older people requires more health conditions to be treated, along with higher demand for long-term care. The elderly are becoming increasingly vulnerable due to the lagging adjustment of the social system to the population ageing, therefore countries may fail to take advantage of these older age groups potential for further life expectancy increase. The observed stagnation in life expectancy at birth increase may be showing that already.

\section{References}

[1] Arriaga, E. E. (1984): Measuring and explaining the change in life expectancies. Demography, 21(1), 83-96. doi: 10.2307/2061029

[2] Arriaga, E. E. (1995): Changing trends in mortality decline during the last decades. In: L. Ruzicka, G. Wunsch, and P. Kane (Eds): Differential Mortality, 105-130. Oxford: Clarendon Press.

[3] Beltrán-Sánches, H., Preston, S. H., and Canudas-Romo, V. (2008): An integrated approach to cause-of-death analysis: Cause-deleted life tables and decompositions of life expectancy. Demographic Research, 19, 1323-1350. doi: $10.4054 /$ DemRes.2008.19.35

[4] Ediev, D. M. (2011): Life expectancy in developed countries is higher than conventionally estimated. Implications from improved measurement of human longevity. Journal of Population Ageing, 4(1), 5-32. doi: $10.1007 /$ s12062-011-9040-x 
[5] Eggleston, K. N. and Fuchs, V. R. (2012): The new demographic transition: Most gains in life expectancy now realized late in life. Journal of Economic Perspectives, 26(3), 137-156. doi: $10.1257 /$ jep.26.3.137

[6] Eurostat Data 1 (2019): https://ec.europa.eu/eurostat/data/database - Database by themes - Population and social conditions - Demography and migration - Mortality - Life expectancy by age and sex. Accessed 15 April 2019.

[7] Eurostat Data 2 (2019): https://ec.europa.eu/eurostat/data/database - Database by themes - Population and social conditions - Health - Causes of death - General mortality - Causes of death - standardised death rate by residence. Accessed 15 April 2019.

[8] Hlebec, V. and Šircelj, M. (2011): Population ageing in Slovenia and social support networks of older people. In A. Hoff (Ed): Population Ageing in Central and Eastern Europe, Societal and Policy Implications, 79-115. London: Routledge.

[9] Ho, J. Y. and Hendi, A. S. (2018): Recent trends in life expectancy across high income countries: Retrospective observational study. BMJ, 362, k2562. doi: 10 . $1136 / \mathrm{bmj} \cdot \mathrm{k} 2562$

[10] ICD-10 International Statistical Classification of Diseases and Related Problems, 10th revision (2016): https://icd.who.int/browse10/2016/en Accessed 15 April 2019.

[11] Kintner, H. J. (2003): The life table. In: D. A. Swanson and J. S. Siegel (Eds): The methods and materials of demography, 301-340. San Diego: Elsevier Science.

[12] Lee, R. (2003): The demographic transition: Three centuries of fundamental change. Journal of Economic Perspectives, 17(4), 167-190. doi: $10.1257 /$ 089533003772034943

[13] Lotrič Dolinar, A., Došenović Bonča, P., and Sambt, J. (2017): Longevity in Slovenia: Past and potential gains in life expectancy by age and causes of death. Zdravstveno varstvo, 56(2), 124-130. doi: 10.1515 /s jph-2017-0016

[14] Mazuy, M., Barbieri, M., Breton, D., d'Albis, H., and Reeve, P. (2016): Recent demographic developments in France: A decline in fertility, an increase in mortality. Population, 71(3), 395-453. doi: 10.3917/popu.1603.0423

[15] Malačič, J. (2006): Demografija - teorija, analiza, metode in modeli. Ljubljana: Ekonomska fakulteta. 
[16] Mayhew, L. and Smith, D. (2015): On the decomposition of life expectancy and limits to life. Population Studies - a Journal of Demography, 69(1), 73-89. doi: $10.1080 / 00324728.2014 .972433$

[17] NIJZ - National Institute for Public Health of Slovenia (2019)

[18] OECD data (2019): https://data.oecd.org/healthstat/life-expectancy-at-birth.htm Life expectancy at birth. Accessed 19 May 2019.

[19] Oeppen, J. and Vaupel, J. W. (2002): Broken Limits to Life Expectancy. Science, 296(5570), 1029-1031. doi: 10.1126/science. 1069675

[20] Pollard, J. H. (1988): On the decomposition of changes in expectation of life and differentials in life expectancy. Demography, 25(2), 265-276. doi: $10.2307 /$ 2061293

[21] Ponnapalli, K. M. (2005): A comparison of different methods for decomposition of changes in expectation of life at birth and differential in life expectancy at birth. Demographic Research, 12, 141-172. doi: 10.4054/DemRes .2005.12.7

[22] Poston, D. L. and Bouvier, L. F. (2017): Population and society: An introduction to demography. Cambridge: University Press.

[23] Pressat, R. (1985): Contribution des écarts de mortalité par âge à la différence des vies moyennes [The significance of variations in mortality by age on differences in life expectancy]. Population, 4, 766-770. doi: 10.3917/popu. p1985.40n4-5.0770

[24] Reed, C., Chaves, S. S., Daily Kirley, P. et al. (2015): Estimating influenza disease burden from population-based surveillance data in the United States. PLOS ONE, 10(3), e0118369. doi: $10.1371 /$ journal.pone.0118369

[25] Riley, J. C. (2001): Rising life expectancy: A global history. Cambridge: University Press.

[26] Scherbov, S. and Ediev, D. (2011): Significance of life table estimates for small populations: Simulation-based study of standard errors. Demographic Research, 24, 527-550. doi: 10.4054/DemRes.2011.24.22

[27] Siegel, J. S., Swanson, D. A., and Shryock, H. S. (2004): The methods and materials of demography. Amsterdam: Elsevier.

[28] SURS - Statistical Office of the Republic of Slovenia (2019) 
[29] SURS - Statistical Office of the Republic of Slovenia SiStat Database (2020): https://pxweb.stat.si/SistatDb/pxweb/en/10_Dem_ soc/10_Dem_soc_05_prebivalstvo_32_Umrljivost_20_ 05L40-trajanje-zivlj/?tablelist=true - Demography and social statistics - Population - Mortality - Life expectancy - Life expectancy by sex, Slovenia, 1960-1961 and from 1986-1987 on, annually. Accessed 4 January 2020.

[30] Tsiatis A. (1975): A nonidentifiability aspect of the problem of competing risks. Proceedings of the National Academy of Sciences of the USA, 72(1), 20-22. doi: $10.1073 /$ pnas. 72.1 .20 